AperTO - Archivio Istituzionale Open Access dell'Università di Torino

\title{
Periodontal health and coronary heart disease: a comment
}

\section{This is the author's manuscript}

Original Citation:

Availability:

This version is available http://hdl.handle.net/2318/1657362

since 2018-10-31T18:22:10Z

Published version:

DOI:10.23736/S0026-4970.17.04116-4

Terms of use:

Open Access

Anyone can freely access the full text of works made available as "Open Access". Works made available under a Creative Commons license can be used according to the terms and conditions of said license. Use of all other works requires consent of the right holder (author or publisher) if not exempted from copyright protection by the applicable law. 


\section{Periodontal health and coronary heart disease: a comment.}

Davide Giuseppe Ribaldone ${ }^{1^{*}}$

${ }^{1}$ Department of Medical Sciences, Division of Gastroenterology, University of Torino, Torino, Italy

Conflicts of interest: none to declare.

${ }^{*}$ Corresponding author: Davide Giuseppe Ribaldone - Department of Medical Sciences, Division of Gastroenterology, University of Torino, C.so Bramante 88 - 10126 Torino - Italy. E-mail: davrib_1998@yahoo.com Tel: +390116335208, Fax: +390116336752.

Key words: Helicobacter pylori, coronary heart disease, periodontitis. 


\section{Dear Sir,}

In a recently published case-control study Al-Rawi and Shahid have investigated the potential association between salivary lipid profile, lipid peroxidation and antioxidants, and the periodontal health status (using the Clinical Periodontal Sum Score or CPSS) of patients with acute coronary heart disease (CHD). Forty patients who had experienced CHD were matched for age, sex and residence to 40 patients without heart diseases. The lipid profile level, lipid peroxidation and antioxidant status were measured in the serum and saliva of all participants together with lactate dehydrogenase $(\mathrm{LDH})$ and $\mathrm{C}$-reactive protein. These parameters were then correlated with the periodontal status of the participants by a multiple linear regression. Salivary total cholesterol, triglycerides, low-density lipoprotein-cholesterol, very-low-density lipoprotein-cholesterol, malondialdehyde, uric acid, superoxide dismutase and LDH levels increased with the upper tertile of the CPSS, while salivary high-density lipoprotein-cholesterol decreased with the upper tertile of the CPSS. The authors concluded that periodontal status could be considered an independent risk factor for acute CHD. ${ }^{1}$

These results confirmed what is well known in the context of periodontal infections and $\mathrm{CHD}^{2}$ but could be expanded to other infections. Another example is that from Helicobacter pylori $(H$. pylori). ${ }^{3}$ H. pylori infection is a chronic one, acquired during childhood as a rule, and associated with low socio-economic class. The habitat of the bacterium is the stomach, where it is the major causal factor of gastritis, peptic ulcer, precancerous lesions, and a necessary but insufficient cause gastric cancer. ${ }^{4}$ Moreover, H. pylori has been involved in diverse aspects of several extragastric manifestations, including CHD. In this context, although currently available data do not prove in an unequivocal manner its role in the pathogenic mechanism of $\mathrm{CHD}$, any potential relationship cannot be ruled out. ${ }^{3}$ A number of studies have reported conflicting results arising from several sources. From an epidemiological point of view, numerous discordances due to the lack of homogeneity emerged. There was a high degree of heterogeneity in the definition of CHD, the control groups 
were biased, hence allowing for large variations in the adjustment of potential confounding factors. From a statistical point of view, often the sample size was small, with limitations and influence on the results due to potential $\alpha$ or $\beta$ errors. From a clinical point of view, the main cause of heterogeneity stemmed from differences among heart diseases included in the studies: acute myocardial infarction, chronic CHD, angina, abnormalities in ECG, or total mortality due to any cardiovascular cause. Moreover, studies on the relationship between CHD and particular strains of the microorganism, characterized by a higher virulence have also given controversial results. ${ }^{3} \mathrm{~A}$ crucial question deals with possible pathogenic mechanisms through with the bacterium could be involved in CHD. H. pylori genomic material has been detected in the plaque only in sporadic occasions, in contrast to Chlamydia pneumoniae. Therefore, the hypothesis of an indirect pathway has been raised. Several mechanisms of damage have been proposed. Indeed, the long-term inflammation generated by $H$. pylori might raise cytokine levels in the bloodstream, and consequently, activate fibroblast and smooth muscle cell proliferation. It is improbable that the lipid profile or fibrinogen levels, as well as circulating markers of inflammation related to artery atherosclerosis, could be influenced by the bacterium. It has been shown that $H$. pylori binds von Willebrand factor and interacts with glycoprotein Ib to induce platelet aggregation. ${ }^{3}$ Hence, the speculation that the infection might induce platelet and immune activation mediated by cytokines, such as interleukin (IL)-1, IL-6 and tumor necrosis factor (TNF)- $\alpha$. Cytokines are intercellular signaling polypeptides, stimulators of the production of most acute-phase proteins. This step could play an important role in platelet adhesion and aggregation leading to plaque vulnerability and eliciting acute ischemic events. While atherosclerosis is an inflammatory disease in which immune mechanisms interact with metabolic factors to initiate, propagate, and activate lesions in the arterial tree, endothelial dysfunction is an early key event in the onset of acute coronary syndrome. Thus, the different features and presentations of CHD should be considered. ${ }^{2}$ 
Because CHD is the outcome of a multiplicity of factors, many of which with only a limited individual effect, complete understanding of causation is difficult. Moreover, since at least in the animal model a relationship between intestinal microbiota and myocardial infarction has been shown, ${ }^{3}$ and considering that the human bowel is the largest reservoir of microbes (it contains trillions of bacteria) in the body, with remarkable relevance for the human health, ${ }^{5}$ further studies should include the consideration of potential alterations of the physiologic intestinal microbiota.

\section{References}

1. Al-Rawi NH, Shahid AM. Oxidative stress, antioxidants, and lipid profile in the serum and saliva of individuals with coronary heart disease: is there a link with periodontal health? Minerva Stomatol 2017;66:212-25.

2. Fardi A, Papadimitriou D. Periodontal and atherosclerosis-induced diseases. Int Angiol 2007; 26:197-205.

3. Ribaldone DG, Fagoonee S, Hickman I, Altruda F, Saracco GM, Pellicano R. Helicobacter pylori infection and ischemic heart disease: could experimental data lead to clinical studies? Minerva Cardioangiol 2016;64:688-98.

4. Pellicano R, Ribaldone DG, Fagoonee S, Astegiano M, Saracco G, Mégraud F. A 2016 panorama of Helicobacter pylori infection: key messages for clinicians. Panminerva Med 2016;58:304-17.

5. Loguercio C. About gut microbiota: why? Minerva Gastroenterol Dietol 2017;63:327-28. 